\title{
CARACTERIZAÇÕES FÍSICAS E FLUIDODINÂMICAS DAS SEMENTES DE CEVADA AO LONGO DO PROCESSO DE POLIMENTO
}

\author{
M. P. FELIZARDO ${ }^{1 *}$, J. T. FREIRE ${ }^{1}$ \\ ${ }^{1}$ Universidade Federal de São Carlos, Departamento de Engenharia Química \\ e-mail:mpfelizardo@ufscar.br
}

\begin{abstract}
RESUMO
Devido a escassez dos estudos sobre os efeitos do polimento nas características das sementes de cevada, o objetivo deste trabalho foi realizar as caracterizações físicas e fluidodinâmicas das sementes de cevada ao longo do processo de polimento. Para realizar o processo de polimento foi adaptado o tambor de um moinho de bolas, colocando lixas de granulometria 80 nas suas paredes para aumentar o atrito entre a parede e as sementes. As propriedades físicas medidas para avaliação do polimento foram: dimensões e forma das sementes e massa específica do leito compactado, estas medidas foram realizadas em triplicata em intervalos de 24 horas de polimento. As medidas das propriedades fluidodinâmicas em leito fixo e fluidizado foram com amostras obtidas de duas corridas de polimento, com três repetições e para intervalos de tempo de polimento de 48 horas. Ao longo do polimento as dimensões das sementes diminuem, tendo uma redução da esfericidade, aumento da massa específica e redução da permeabilidade e velocidade de mínima fluidização. Durante os períodos iniciais de polimento os tecidos de proteção (casca, pericarpo e testa) oferecem uma resistência mecânica ao polimento, confirmando suas características funcionais de proteção ao embrião e endosperma nas sementes.
\end{abstract}

\section{INTRODUÇÃO}

Recentemente, a principal forma de consumo da cevada é para a malteação na indústria cervejeira.

Segundo Baik e Ullrich (2008) 2\% das sementes de cevada produzidas mundialmente são utilizadas para alimentação. Para esta forma de consumo, as sementes devem ser polidas para a retirada das camadas externas ao endosperma (pericarpo, testa e casca).

Porém, dentre os trabalhos encontrados na literatura não se tem dados sobre os efeitos do processo de polimento nas características físicas das sementes e fluidodinâmicas do meio poroso formado por estas sementes.

Entretanto, espera-se que, o polimento das sementes de cevada cause a redução das dimensões das sementes, podendo alterar a forma, massa específica do leito e consequentemente as características fluidodinâmicas de um meio poroso constituído por estas partículas.

Com base nisto, o objetivo deste trabalho foi realizar as caracterizações físicas e fluidodinâmicas das sementes de cevada ao longo do processo de polimento.

\section{MATERIAIS E MÉTODOS}

A seguir, os materiais métodos, para alcançar o objetivo deste trabalho, foram descritos. 


\subsection{Sementes de Cevada}

As sementes de cevada foram obtidas da empresa Agromalte e colhidas no estado do Paraná, estas foram armazenadas em temperatura de aproximadamente $4^{\circ} \mathrm{C}$ até a sua utilização (CARVALHO e NAKAGAWA, 1980).

O conteúdo de umidade em base úmida das sementes armazenadas foi de $(7,41 \pm 0,17) \%$.

Para a limpeza destas sementes, utilizou-se o processo de elutriação para a retirada de materiais leves e seleção manual para a retirada dos demais resíduos.

\subsection{Polimento das Sementes}

Para o processo de polimento das sementes de cevada foi adaptado um moinho de bolas, da marca Stoneware, modelo $\mathrm{OH} 44413$.

As paredes do tambor foram revestidas com lixas de granulometria 80 (3M 230U), aumentando o atrito das sementes com as paredes durante a rotação.

A massa inicial das sementes foi de aproximadamente 350 gramas. As medidas das massas das sementes em relação ao tempo de polimento foram realizadas em intervalos de 24 horas, bem como, as medidas das propriedades físicas.

Ao retirar o material do moinho, a elutriação das partículas foi realizada, para a retirada do pó que estava aderido na superfície das sementes polidas.

Antes de reiniciar o processo de polimento, as lixas que revestiam a parede do tambor eram trocadas e iniciava-se o processo por mais 24 horas.

O polimento foi finalizado quando se obteve uma redução de massa de $50 \%$, que segundo Mayolle et al. (2012) para estes valor tem-se uma retirada total da casca.

\subsection{Propriedades Físicas}

As propriedades físicas foram medidas para as sementes inteiras e para as sementes com diferentes tempos de polimento.

Para a medida do comprimento (C) e largura (L) das sementes foram utilizadas imagens, obtidas por câmera fotográfica digital da marca Kodak, modelo EasyShare C182.

E a espessura (E) das sementes foi obtida por meio da medida com paquímetro digital de precisão de $0,01 \mathrm{~mm}$.

Para a estimativa da esfericidade utilizou-se a Equação 1 (MASSARANI e PEÇANHA, 1988).

$\phi=\frac{\sqrt[3]{C . L . E}}{C}$

As medidas das dimensões e estimativas de forma foram realizadas para 45 sementes.

Para a medida da massa específica do leito utilizou-se a técnica de empacotamento de um leito de partículas em proveta graduada.

Impactos com condições aproximada a queda livre de uma altura de $8 \mathrm{~cm}$ foram realizados, para o empacotamento das partículas. Este volume empacotado foi obtido pela graduação da proveta. Com isto, pela relação de massa e volume obteve-se a massa específica do leito.

\subsection{Avaliação Fluidodinâmica}

\subsubsection{Equipamento}

$O$ equipamento esquematizado na Figura 1 foi utilizado para avaliação da fluidodinâmica em leito fixo e fluidizado das sementes de cevada inteiras e polidas.

A esquematização mostra o soprador de 2 HP de potência (1), que escoa o ar por uma tubulação de 2 pol. de diâmetro constante ao longo de toda tubulação. 
Figura 1 - Esquematização da unidade experimental para avaliação fluidodinâmica.

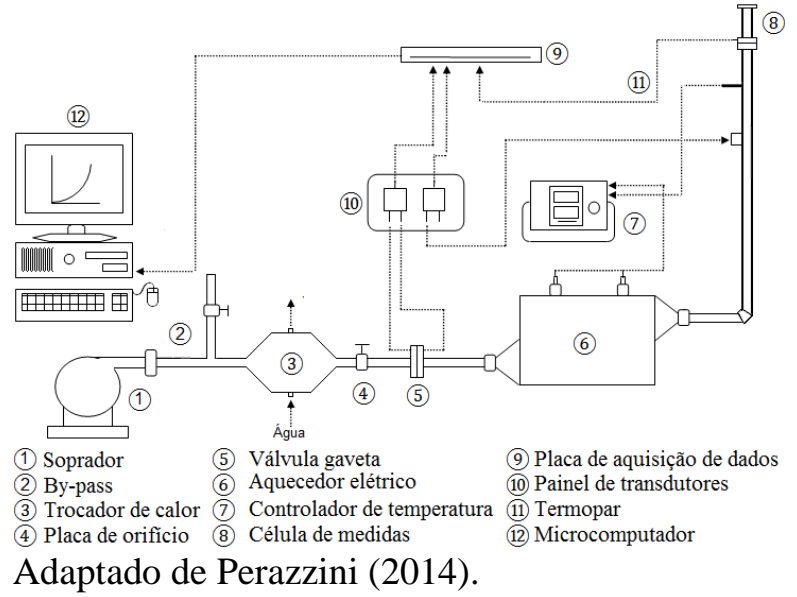

A vazão de escoamento foi controlada por válvulas do tipo gaveta de 2 pol. de diâmetro (5) constituindo um sistema "bypass"(2) e para a medida da vazão utilizou-se uma placa de orifício (4).

Antes da entrada na célula de medida (8) tem-se um termopar encapsulado tipo T (11), esta medida foi utilizada pelo controlador de temperatura Flyever FE50s (7), que teve a função de variar a potência fornecida as resistências do aquecedor elétrico (6) para controlar a temperatura do ar.

Para redução da temperatura do ar que vem do soprador, tem-se o sistema de trocador de calor, tipo casco-tubo (3).

Para a verificação da queda de pressão na placa de orifício (4) foram utilizados transdutores de pressão (10) da marca Auto Tran Incorporated, com faixa operacional de 0 a 5 pol. de coluna de água.

A vazão do ar foi calculada em função da queda de pressão na placa de orifício, conforme calibração com tubo venturi padrão.

A queda de pressão no leito foi obtida através de transdutores da mesma marca, com faixa operacional de 0 a 10 pol. de coluna de água.

Os dados dos transdutores serão transferidos por meio de uma placa de aquisição (9) da Personal daq/56 para um microcomputador (12).

Para a homogeneização da velocidade do ar na seção transversal do tubo foi utilizada 5 placas defletoras, onde a distância entre a base da célula de medida e a última placa defletora foi de aproximadamente 20 vezes o diâmetro do tubo. Desta forma, garantindo o desenvolvimento do escoamento do ar.

A célula de medida foi construída em acrílico, para visualização do regime de escoamento, com seção circular de $5 \mathrm{~cm}$ de diâmetro e $30 \mathrm{~cm}$ de altura

\subsubsection{Avaliação Fluidodinâmica do Leito Fixo \\ O empacotamento dos materiais na} célula de medida foi realizado conforme Zotin (1985).

Realizando inúmeros impactos com a célula de medida para acomodação das partículas. Os impactos foram interrompidos quando não houve mais variação do volume do leito de sementes.

A permeabilidade do leito de sementes foi calculada com o ajuste da Equação 2 aos dados de queda de pressão no leito em função da velocidade superficial do ar (MASSARANI, 1989).

$\frac{\Delta P}{H}=\frac{\mu}{\kappa} \cdot v+\frac{c \cdot \rho}{\sqrt{\kappa}} \cdot v^{2}$

Para as propriedades do ar, os valores foram de $1,85 \times 10^{-5} \mathrm{~N} . \mathrm{s} / \mathrm{m}^{2}$ para viscosidade dinâmica do ar e $1,16 \mathrm{~kg} / \mathrm{m}^{3}$ para massa específica do ar, estes valores foram obtidos por meio de Incropera e Dewitt (2003) para temperatura de aproximadamente $27^{\circ} \mathrm{C}$.

\subsubsection{Avaliação Fluidodinâmica do Leito} Fluidizado

Para a realização dos experimentos em leito fluidizado, a velocidade do ar foi regulada em aproximadamente $4 \mathrm{~m} / \mathrm{s}$ e então a 
válvula foi sendo fechada até que a velocidade do ar no leito fosse completamente interrompida.

Para cada velocidade foram feitas 50 medidas de queda de pressão no leito por meio de transdutor de pressão (Figura 1).

A velocidade de mínima fluidização foi determinada com base na metodologia das retas tangentes. Onde a velocidade de mínima fluidização foi obtida com base na intersecção entre a reta tangente ao leito fixo e a reta tangente ao leito fluidizado.

A avaliação fluidodinâmica para leito fixo e fluidizado foi com meios porosos constituídos de sementes inteiras e polidas por 2, 4, 6 e 8 dias.

Para as sementes polidas, para cada tempo de polimento, tinham-se duas amostras provenientes de diferentes corridas, desta forma, pode-se avaliar a reprodutibilidade do polimento.

Para cada uma, destas amostras foram realizadas três repetições dos ensaios de queda de pressão no leito em função da velocidade superficial do ar, com isto, podese avaliar a reprodutibilidade destes testes fluidodinâmicos.

Os ensaios fluidodinâmicos para leito fixo e fluidizado foram realizados com altura de leito fixo inicial constante de aproximadamente $3,5 \mathrm{~cm}$ e a temperatura do ar foi de aproximadamente $27^{\circ} \mathrm{C}$.

Uma avaliação preliminar da unidade experimental foi realizada, conforme Lima (2009), utilizando partículas esféricas de vidro "ballotini" com diâmetro médio de 925 $\mu \mathrm{m}$, densidade de $2,5 \mathrm{~g} / \mathrm{cm}^{3}$ e altura estática de leito de $3,5 \mathrm{~cm}$.

$\mathrm{O}$ valor da velocidade mínima fluidização foi obtido com base no método das retas tangentes, conforme descrito anteriormente e comparado com os resultados obtidos por Lima (2009).

\section{RESULTADOS E DISCUSSÕES}

\subsection{Cinética de Polimento das Sementes}

Os resultados da massa relativa $\left(\mathrm{m}_{\mathrm{t}} / \mathrm{m}_{\mathrm{o}}\right)$ das sementes de cevada em função do tempo de polimento estão apresentados na Figura 2.

Figura 2 - Massa relativa em função do tempo de polimento.

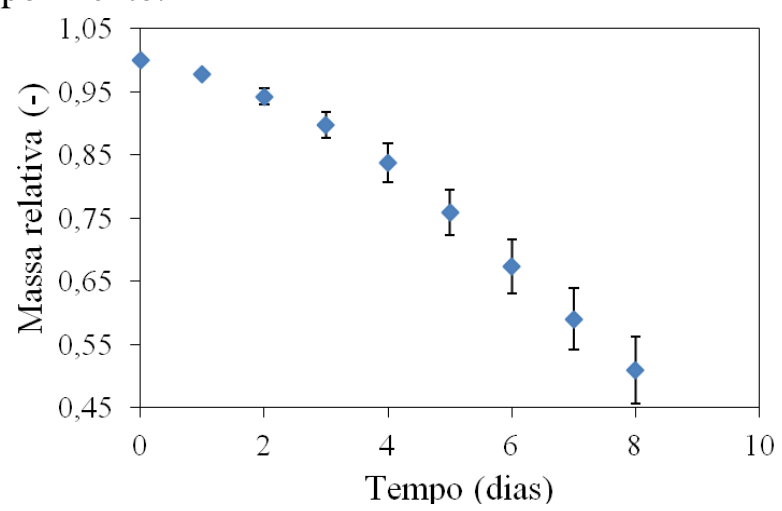

Fonte: Pessoal (2015).

Pode-se observar na Figura 2 que, quanto maior o tempo de polimento maior foram os desvios da medida da massa das sementes, pois com a prolongação do processo de polimento surgem alguns efeitos, como a quebra das sementes.

Além disto, algumas sementes podem ter ficado aderidas as paredes das lixas ou no meio do pó produzido pelo lixamento, que foram descartados durante a limpeza do tambor e a troca das lixas a cada 24 horas (1 dia).

Para uma avaliação da cinética de redução da massa das sementes durante o polimento, calculou-se a taxa de redução da massa, por meio da Equação 3 (BEMROSE e BRIDGEWATER, 1987).

$\psi_{t}=\frac{m(t+1)-m(t)}{(t+1)-t}$

Na Figura 3, têm-se as taxas de redução de massa em relação ao tempo de polimento. 
Constata-se por meio da Figura 3 que, para os quatro primeiros dias de polimento a taxa de redução de massa teve uma variação em relação ao tempo. Isto se deve, pois neste período de tempo o polimento estava sendo realizado nas camadas externas ao endosperma: casca, pericarpo e testa.

Através da avaliação deste resultado, pode-se inferir que, os tecidos externos são mecanicamente mais resistentes do que o endosperma e o embrião.

Já que, nos períodos iniciais com as mesmas condições operacionais tem-se uma menor taxa de retirada de massa, aumentando esta taxa com a retirada destes tecidos.

Figura 3 - Taxa da redução de massa em relação ao tempo de polimento.

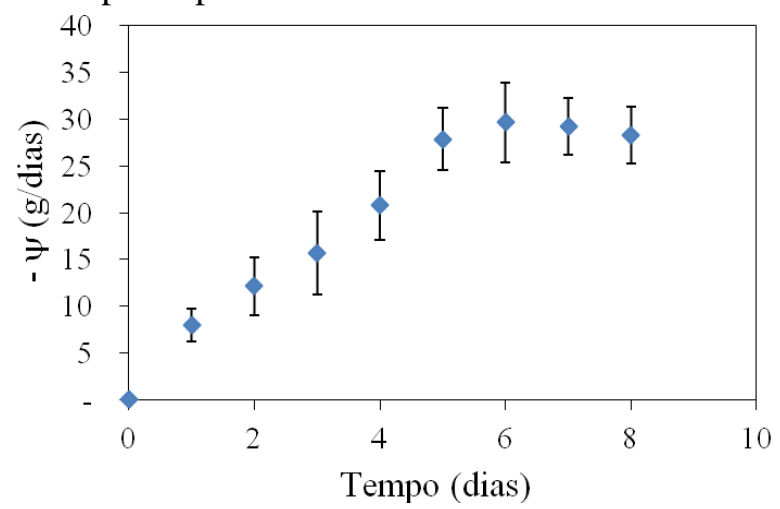

Fonte: Pessoal (2015).

Isto é coerente, pois os tecidos como: casca, testa e pericarpo, são partes das sementes cevada com função de proteção do endosperma e embrião. Assim sendo, oferece uma resistência mecânica a uma força aplicada sobre a superfície da semente, para que não ocorram danos ao endosperma $\mathrm{e}$ embrião.

Portanto, de acordo com a Figura 3, a partir do quarto dia de polimento, os efeitos de resistência mecânica dos tecidos externos ao endosperma no polimento foram reduzidos, sendo aproximadamente não significativos.

$\mathrm{Na}$ Figura 4, têm-se as imagens das superfícies das lixas e das sementes ao longo do tempo de polimento em sequência cronológica.

Partindo da esquerda com a semente sem polimento e seguindo para a direita conforme se aumenta o tempo de polimento, em intervalos de tempo de 24 horas.

Figura 4 - Imagens das (A) superfícies das lixas e das (B) sementes ao longo dos dias de polimento.

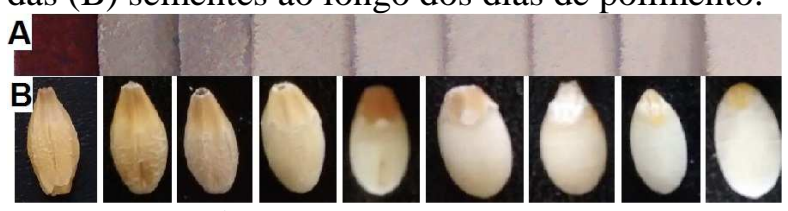

Fonte: Pessoal (2015).

$\mathrm{Na}$ Figura 4a observa-se que, as superfícies das lixas após o polimento estavam cada vez mais claras, isto indica o polimento do endosperma, que apresenta cor clara tendendo ao branco, como pode ser observado com a última semente da Figura $4 b$ (com oito dias de polimento).

Para as imagens das sementes, entre o terceiro e o quarto dia de polimento, observase a presença da casca apenas nas extremidades longitudinais das sementes.

Portanto, por meio desta avaliação constatamos que, aproximadamente em 4 dias de polimento retirou-se a maior parte da casca envolta no endosperma, confirmando a discussão realizada dos resultados apresentados na Figura 3.

A seguir, apresentaremos os resultados das propriedades físicas em relação ao tempo de polimento.

\subsection{Propriedades físicas}

Os resultados das propriedades físicas foram apresentados na forma relativa, ou seja, pela razão entre a medida em um determinado tempo de polimento e a medida da semente inteira.

Na Figura 5 são mostrados os resultados do comprimento, largura e espessura das sementes de cevada em função do tempo de polimento. 
Figura 5 - Medidas de comprimento, espessura e largura relativas em relação ao tempo de polimento.

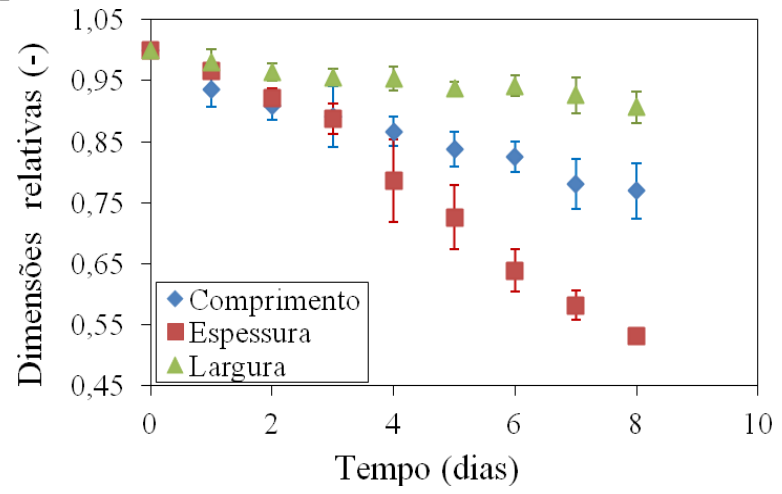

Fonte: Pessoal (2015).

Com base na Figura 5, constata-se que a espessura teve uma maior redução do que a largura e comprimento.

Isto se deve, a forma da partícula, em que a posição de repouso das sementes de cevada no tambor proporcionava um contato entre a superfície da lixa e da semente que acarretava em uma maior redução da espessura das sementes em relação a largura e comprimento.

Este efeito do polimento sobre as dimensões das sementes influenciou na esfericidade, como pode ser visto na Figura 6, que ilustra a esfericidade relativa em função do tempo de polimento.

Figura 6 - Esfericidade relativa em função do tempo de polimento.

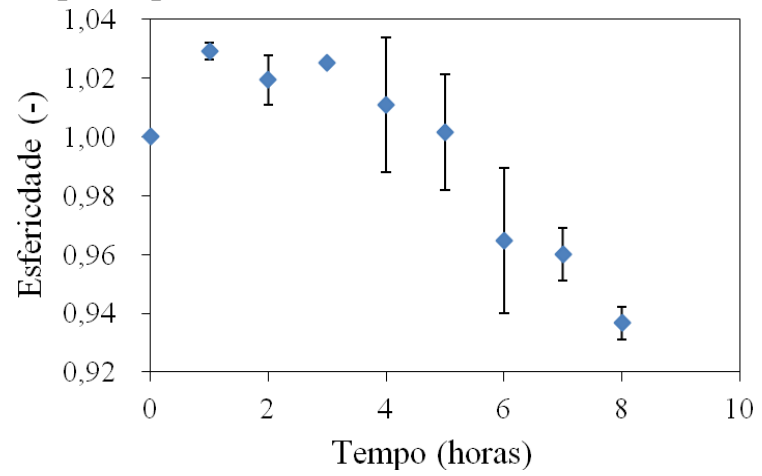

Fonte: Pessoal (2015).
Na Figura 7, tem-se a massa específica relativa do leito em função do tempo de polimento.

Figura 7- Massa específica relativa do leito em função do tempo de polimento.

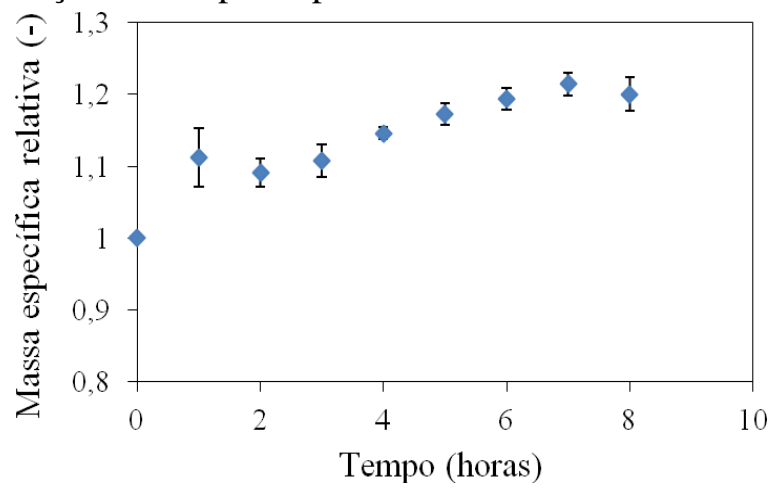

Fonte: Pessoal (2015).

Observa-se na Figura 7 que, para o primeiro dia de polimento, a massa específica teve um aumento significativo e então permaneceu constante até o terceiro dia.

No primeiro dia, o principal efeito do polimento foi a retirada das irregularidades da superfície, pois se observa na Figura 5 que, não houve variação significativa das dimensões das sementes.

Ou seja, o efeito do desbaste das arestas e irregularidades na casca pela lixa, pode justificar o aumento da massa específica do leito entre sementes inteiras e polidas por 24 horas (1 dia).

Este efeito aumentou a capacidade de rearranjo das partículas, devido a superfícies menos rugosas, aumentando significativamente a massa específica com 24 horas de polimento.

Até o terceiro dia de polimento, tanto as variações das dimensões (Figura 5) quanto a variação da esfericidade (Figura 6) foram pequenas, isto pode ter implicado no comportamento da massa específica do leito em função do tempo de polimento para este mesmo período (Figura 7).

Por meio da Figura 4 verifica-se que, inicialmente a forma da cevada é 
aproximadamente elipsoidal levemente alongada e a partir do quarto dia de polimento esse alongamento foi reduzido.

Esta mudança de forma pode justificar o aumento da massa específica do leito a partir do quarto dia na Figura 7 (MATA e DUARTE, 2002).

Além disto, anteriormente, para a discussão da taxa de redução de massa ao longo do tempo de polimento (Figura 3). Neste mesmo período de tempo de polimento, observou-se que os efeitos da casca foram reduzidos e aproximadamente não significativos.

Portanto, a resistência mecânica ao polimento da casca, reduziu inicialmente, os efeitos do polimento sobre a massa específica do leito e a esfericidade das sementes.

\subsection{Avaliação Fluidodinâmica}

A velocidade mínima de fluidização para esferas de vidro "ballotini" com diâmetro médio de $925 \mu \mathrm{m}$, densidade de $2,5 \mathrm{~g} / \mathrm{cm}^{3} \mathrm{e}$ altura estática de leito de $3,5 \mathrm{~cm}$ foi de $(0,41 \pm 0,04) \mathrm{m} / \mathrm{s}$.

Para Lima (2009) com as mesmas condições operacionais e partículas, a velocidade mínima fluidização foi de $(0,47 \pm 0,01) \mathrm{m} / \mathrm{s}$.

$\mathrm{O}$ autor ainda afirma que, para a correlação de Wen e Yu para estas condições, o valor da velocidade mínima de fluidização é de $0,46 \mathrm{~m} / \mathrm{s}$. Portanto, este resultado experimental mostra que a unidade apresenta boa concordância operacional com o que é apresentado na literatura.

\subsubsection{Leito Fixo}

A Figura 8 mostra os resultados para permeabilidade em função do tempo de polimento.

Na Figura 8, a diferença entre as médias de permeabilidade obtidas para o polimento e a réplica 1 no mesmo tempo de polimento foi menor que os desvios.
Portanto, comprovando a reprodução dos experimentos de polimento e de fluidodinâmica em leito fixo.

Figura 8 - Permeabilidade em função do tempo de polimento.

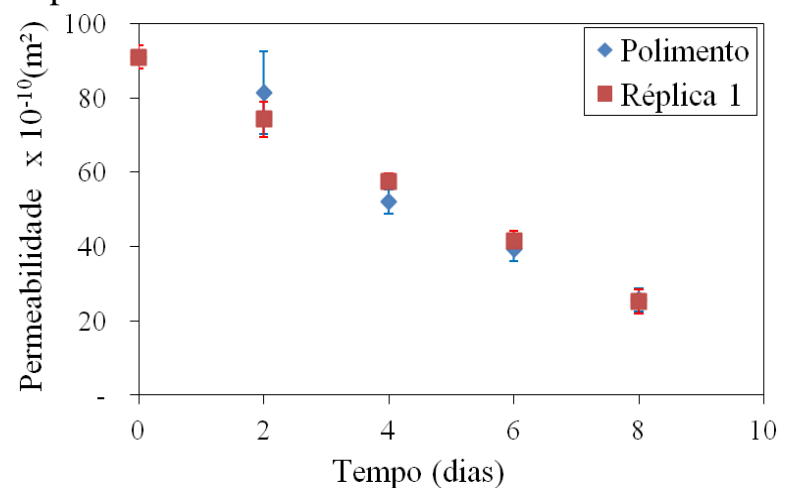

Fonte: Pessoal (2015).

A variação da permeabilidade com o tempo de polimento (Figura 8) mostra uma relação com os resultados apresentados para a massa específica do leito (Figura 7).

Com o aumento do tempo de polimento a massa específica do leito aumentou, ou seja, a porosidade do meio poroso era menor, aumentando a resistência ao escoamento do ar.

$\mathrm{Na}$ Figura 9 são apresentados os resultados do coeficiente de Forchheimer (fator c, Equação 2) em relação ao tempo de polimento.

Figura 9- Coeficiente de Forchheimer em relação ao tempo de polimento.

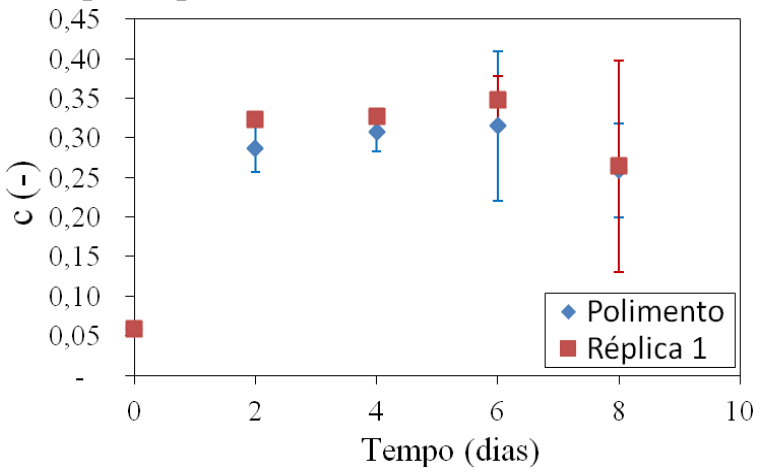

Fonte: Pessoal (2015). 
Segundo Massarani (1989), o coeficiente de Forchheimer está relacionado com a interação entre o fluido e as paredes dos poros, ou seja, relacionada a tortuosidade e estrutura do meio poroso.

Pode-se observar na Figura 9, que para tempos maiores que 4 dias aumentou-se o desvio padrão das medidas do fator c.

Isto pode estar associado a redução da casca neste tempo de polimento, onde as maiores variações na esfericidade da partícula e na massa específica do leito podem ter influenciado nos desvios para este parâmetro.

Além disto, verifica-se que as diferenças entre as médias do fator c ao longo do tempo de polimento são menores do que os desvios.

Portanto, o fator c apresentou variação apenas entre as sementes inteiras $\mathrm{e}$ as sementes polidas. Mas, não apresentou variação estatísticamente significativa entre os tempos de polimento.

Pode se verificar na Figura 9, que a variação do fator $\mathrm{c}$ entre sementes inteiras e com dois dias de polimento foi de aproximadamente seis vezes.

Considerando que a esfericidade e as dimensões das partículas não apresentaram variação tão significativa com 24 horas de polimento, pode-se inferir que, parte desta variação do coeficiente de Forchheimer está relacionada a variação na superfície das partículas.

Com o polimento teve-se a redução das irregularidades na superfície das partículas, aumentou-se a interação entre o gás e o meio poroso e isto pode ter aumentado o valor do coeficiente de Forchheimer.

Além de que, a variação pouco significativa deste fator com o tempo de polimento indica que ele não teve relação direta com as variações de esfericidade e dimensões das partículas que compõem o leito fixo.

\subsubsection{Leito Fluidizado}

$\mathrm{Na}$ Figura 10 são apresentados os resultados da queda de pressão adimensionalizada em função da velocidade superficial do ar, parametrizados com diferentes tempos de polimento e sementes inteiras.

Figura 10 - Adimensional da queda de pressão em função da velocidade do ar, parametrizado em diferentes tempos de polimento.

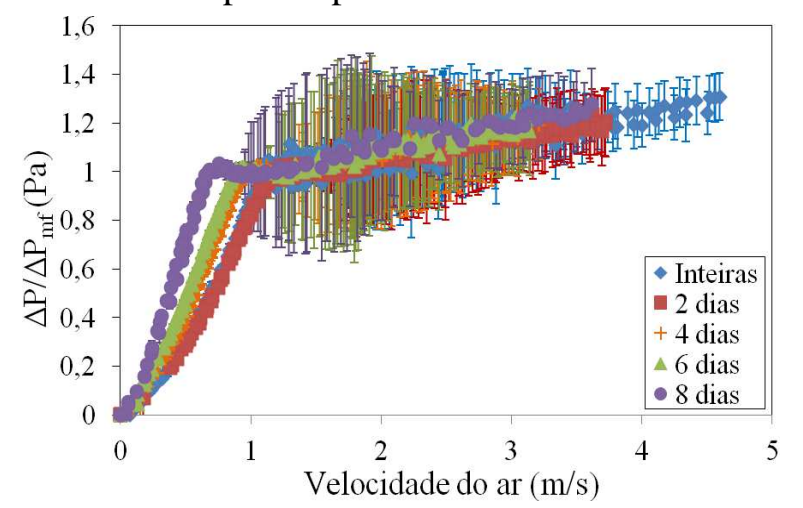

Fonte: Pessoal (2015).

O adimensional da queda de pressão foi calculado por uma relação da queda pressão se e a queda de pressão na mínima fluidização.

Este adimensional foi utilizado para reduzir os efeitos da massa sobre as curvas fluidodinâmicas, pois foram utilizadas alturas constantes de leito estático entre os testes, com a variação da massa específica do leito, teve-se uma variação da massa de partículas no leito.

Conforme a Figura 10, os resultados para diferentes testes de fluidodinâmica, com amostras diferentes, para cada tempo de polimento foram colocados com os mesmos marcadores.

Assim sendo, a sobreposição das curvas mostra que, os experimentos de polimento e fluidodinâmica foram reprodutíveis.

Através destes dados foram obtidas as velocidades de mínima fluidização em função dos tempos de polimento, estes resultados estão na Figura 11. 
Figura 11 - Velocidade de mínima fluidização em função do tempo de polimento.

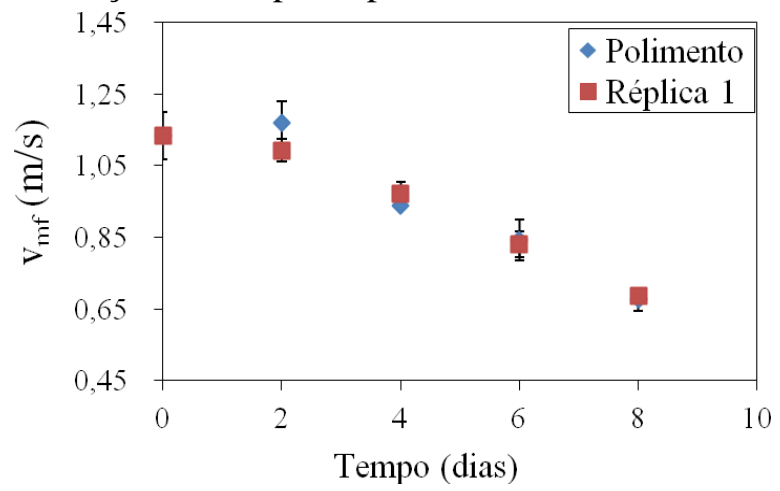

Fonte: Pessoal (2015).

Pode-se constatar que, existe uma similaridade entre o comportamento da curva de velocidade de mínima fluidização (Figura 11), esfericidade (Figura 6) e massa específica do leito (Figura 7) em função do tempo de polimento. Pois, todas estas medidas até o terceiro dia foram aproximadamente constante.

Porém, segundo Lima (2009) a influência de propriedades físicas na velocidade mínima fluidização é um assunto muito complexo, pois esta velocidade de trânsição tem vários fenômenos físicos envolvidos.

\section{CONCLUSÕES}

Com base nos resultados e discussões realizados, pode-se concluir que:

- A casca apresentou um efeito de resistência mecânica ao polimento e esta foi predominante nos períodos iniciais do polimento, apresentando influência sobre as variações das propriedades físicas das partículas e do leito;

- O coeficiente de Forchheimer foi constante ao longo do tempo de polimento, mas aumentou significativamente quando comparada as sementes polidas com as sementes inteiras;
- Entre diferentes experimentos de polimento, os resultados dos parâmetros fluidodinâmicos mostraram que houve reprodutibilidade, $\mathrm{e}$

- A velocidade de mínima fluidização teve influência do polimento, que foi uma consequência das alterações das propriedades físicas das sementes.

\section{NOMENCLATURA}$$
\mathrm{c}
$$

C

Coeficiente de Forchheimer.

Comprimento da semente.

(mm)

E Espessura das sementes.

(mm)

$\mathrm{H} \quad$ Altura do leito fixo.

L Largura da semente.

M Massa das sementes. polimento.

$\mathrm{m}_{\mathrm{o}} \quad$ Massa inicial das sementes (inteiras)

T Tempo de polimento.

V Velocidade do ar.

Velocidade de mínima fluidização.

$(\mathrm{m} / \mathrm{s})$

\section{Letras gregas}

$\begin{array}{llr}\Delta \mathrm{P} & \text { Queda de pressão no leito. } & (\mathrm{Pa}) \\ \Delta \mathrm{P}_{\mathrm{mf}} & \begin{array}{l}\text { Queda de pressão no leito na } \\ \text { mínima fluidização. }\end{array} & (\mathrm{Pa}) \\ \kappa & \text { Permeabilidade do leito fixo. } & \left(\mathrm{m}^{2}\right) \\ \mu & \text { Viscosidade dinâmica do ar. } & \left(\mathrm{N} . \mathrm{s} / \mathrm{m}^{2}\right) \\ \rho & \text { Massa específica do ar. } & \left(\mathrm{kg} / \mathrm{m}^{3}\right) \\ \psi & \text { Taxa de redução de massa } & (\mathrm{g} / \mathrm{dias})\end{array}$

\section{REFERÊNCIAS}

BAIK, B. K.; ULLRICH, S. E. Barley for food: Characteristics, improvement, and renewed interest. Journal of Cereal Science, v. 48, p. 233-242, 2008. 
BEMROSE, C R; BRIDGWATER, J. A review of attrition and attrition test methods. Powder Technology, Netherlands, v. 49, p.97-126, 1987.

CARVALHO, N. M.; NAKAGAWA, J. Sementes: ciência, tecnologia e produção. Campinas: Fundação Cargil, 1980. p. 326.

INCROPERA, F. P.; DeWITT, D. P. Fundamentos de transferência de calor e de massa. 5. ed. Rio de Janeiro: LTC, 2003. $698 \mathrm{p}$.

LIMA, R. de A. B. Fluidodinâmica de leitos fluidizados e vibrofluidizados operando com partículas planas. 2009. 150p. Dissertação (Mestrado Engenharia Química) Universidade Federal de São Carlos, São Carlos, 2009.

MATA, M. E. R. M. C.; DUARTE, M. E. M. Porosidade intergranular de produtos agrícolas. Revista Brasileira de Produtos Agroindustriais, Campina Grande, PB, v. 4, n. 1, p. 79-93, 2002.

MASSARANI, G. Aspectos da fluidodinâmica em meios porosos. Rio de Janeiro: Revista Brasileira de Engenharia, 1989. 96 p.

MASSARANI, G.; PEÇANHA, R. P. Dimensão característica e forma de partículas. In: ENCONTRO SOBRE ESCOAMENTO EM MEIOS POROSOS , 14., 1988, Anais... Campinas: Universidade Estadual de Campinas, 1988. p. 302 - 312.

MAYOLLE, J. E. et al. Water diffusion and enzyme activities during malting of barley grains: A relationship assesment. Journal of Food Engineering, v. 109, p. 358-365, 2012.

PERAZZINI, H. Secagem de sólidos porosos granulares. 2014. 190p. (Doutorado em
Engenharia Química) - Universidade Federal de São Carlos, São Carlos, 2014.

\section{AGRADECIMENTOS}

Os autores agradecem a Cooperativa Agrária Agroindustrial pela inestimável contribuição ao presente trabalho através do fornecimento dos lotes de cevada para as análises e ao CNPq e a CAPES pelo auxílio financeiro. 